Naamsestraat 61 - bus 3550 B-3000 Leuven - BELGIUM Tel : 32-16-326661 vives@econ.kuleuven.be

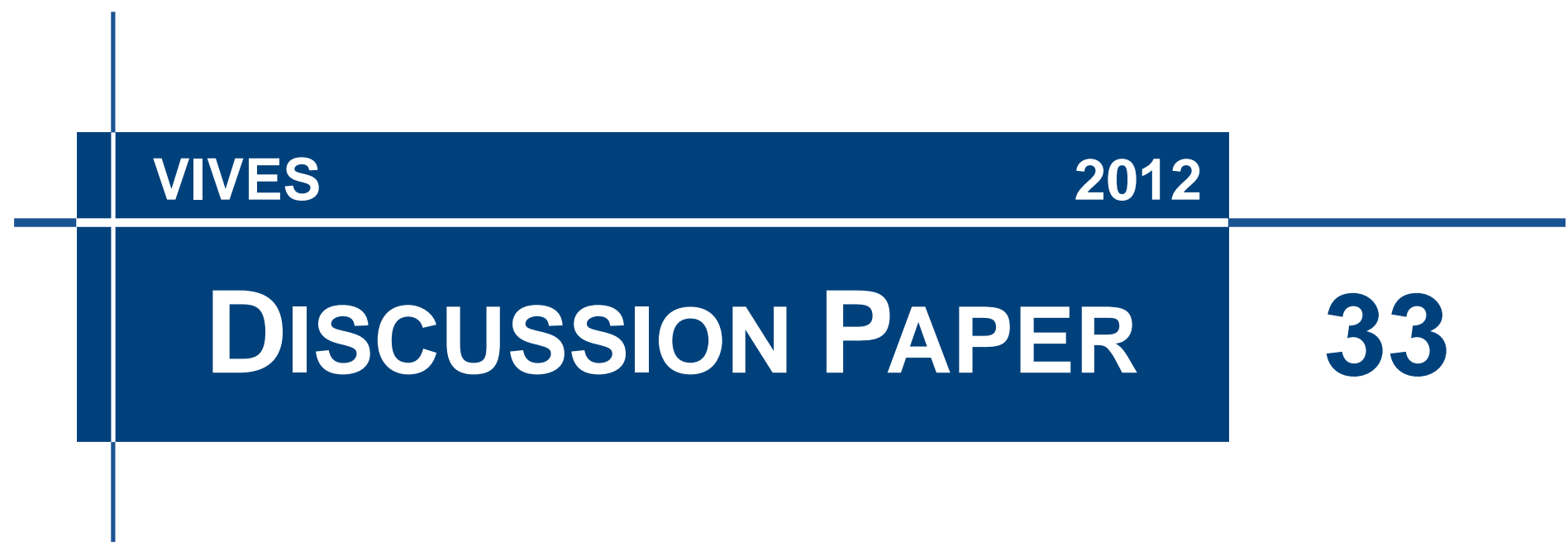

\title{
A Gravity Equation for
} Commuting

\author{
Damiaan Persyn \\ Wouter Torfs
}




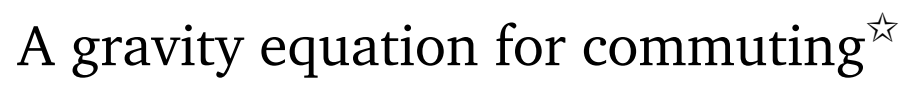

\author{
Damiaan Persyn $^{\mathrm{a}, \mathrm{b}}$, Wouter Torfs ${ }^{\mathrm{a}}$ \\ ${ }^{a}$ University of Leuven, VIVES Center for Regional Economics, Naamsestraat 61, 3000 Leuven \\ ${ }^{b}$ European Commission, DG JRC, Calle Inca Garcilaso 3, 41092 Seville, Spain
}

\begin{abstract}
This paper derives a gravity equation for commuter flows from a simple spatial labor market model, and uses it to identify the effect of regional borders on commuting. This structural approach allows us to identify the relevant control variables and sources of potential omitted variable bias. The model is estimated by means of a negative binomial regression using Belgian data on intermunicipality commuting. We find that regional borders exert a sizable residual deterrent effect on commuting. This border-effect differs significantly between regions and depends on the direction in which the border is crossed.
\end{abstract}

\section{Introduction}

Commuting is an important spatial equilibrating mechanism in the labor market. It reduces disparities in regional labor market outcomes such as unemployment rates and wages. However, commuting is costly. One can think of obvious costs that are directly related to the commuting distance, such as straightforward travel expenses or the opportunity cost of a lengthy daily commute. Additionally, there exist less tangible but nonetheless substantial costs when a worker commutes to a different region. These costs could arise from, for example, informational deficiencies, linguistic barriers or cultural differences. They explain the difference between the expected commuting flows between regions based on purely economic and geographic factors, and observed commuting flows. Such 'missing interregional commuting' suggests an inefficient spatial allocation of labor, implying that large welfare gains can be obtained from policies aimed at removing these barriers, for example by improving information exchange related to interregional job search, adjusting the regional skill structure, investing in language

\footnotetext{
${ }^{\text {光}}$ We are grateful to Klaus Desmet, Joep Konings, Johannes Van Biesebroeck and VIVES Seminar participants for helpful comments and suggestions. The most recent version of this paper can be found at www.econ.kuleuven.be/wouter.torfs

Email address: wouter.torfs@econ.kuleuven.be (Wouter Torfs)
}

August 24, 2012 
education, etc. This should be especially beneficial for countries with marked differences in regional labor market performance, as is the case with many European countries.

The early trade literature has mostly used ad-hoc gravity-equations (Guest and Cluett, 1976; Flowerdew and Aitkin, 1982; Thorsen and Gitlesen, 1998; Mathä and Wintr, 2007; McArthur, Kleppe, Thorsen, and Ubøe, 2011; Melo, Graham, and Noland, 2011), where the trade flow between two regions or countries depends on some measures of economic mass and distance. Advances in the international trade literature have shown that this approach leads to estimation bias, however. Following Anderson and Van Wincoop (2003) (AvW hereafter), we derive a gravity equation for commuting from a spatial labor market model. This model allows us to identify the relevant control variables and provides a functional form for modeling commuting flows. First, we show that the correct controls for economic mass are different from those commonly used in the literature. Second, as in AVW, the resulting gravity equation shows that the size of a commuter flow between two regions depends not only on the characteristics of both regions, but also on their respective geographic surroundings. Neglecting to control for this would again result in estimation bias. Other authors before us have made creditable attempts toward estimating gravity equations for commuting while taking into account the distribution of economic activity in the surrounding regions by controlling for accessibility measures (Fotheringham, 1981; Thorsen and Gitlesen, 1998). Such ad-hoc approaches equally result in estimation bias, however (see Baier and Bergstrand, 2009).

Our micro-founded gravity equation is subsequently empirically estimated by means of a count model. Count models allow for zero as a possible outcome and avoid the biases introduced by estimating log-linearized models in the presence of heteroskedasticity (Silva and Tenreyro, 2006). The empirical application uses aggregate data on commuting flows between 580 Belgian municipalities ${ }^{1}$ in 2008. Belgium is an interesting case for the study at hand for a number of reasons:

Regional borders are important in Belgium. Belgium is a multilingual country, consisting of three NUTS1 regions; Flanders in the north, and Wallonia in the South are officially unilingually Dutch and French speaking regions, respectively. The central capital region of Brussels is officially bilingual, but de facto a majority of the local population speaks French (Janssens, 2008). Nevertheless, many jobs in Brussels (for example for the central government) require knowledge of both French and Dutch. Belgium is a federal state, with regional governments in each of the three NUTS1 regions. Successive reforms of the Belgian state resulted in an

\footnotetext{
${ }^{1}$ To simplify the analysis, we exclude the 9 municipalities in the small German-speaking Community in Belgium from the analysis.
} 
increasing degree of political independence for the regions, also regarding active labor market policy.

The three Belgian regions are also characterized by strong and persistent differences in economic performance. The capital region of Brussels is unmistakably the center of Belgian economic activity, hosting 17 percent of total Belgian payroll employment. Despite being the most important economic hub in Belgium, the Brussels unemployment rate is the highest in the country. This can also be seen in Figure 1, which shows unemployment rates for 2008 at the municipal level. The Brussels unemployment rate reached 16 percent, whereas unemployment in Flanders was only 3.9 percent. The Walloon unemployment rate, with 10.1 percent, was also significantly higher than in Flanders. The simultaneous presence of a thriving economy and high unemployment in Brussels leads one to suspect that the skill structure of Brussel's residents does not suit the needs of local labor demand. These regional differences in labor market performance arose in the aftermath of the seventies oil-crises and have persisted ever since (Torfs, 2008). It is noteworthy how the linguistic and regional borders in Belgium can be clearly recognized from the municipal unemployment rates in Figure 1. Municipalities in Brussels and Wallonia consistently have higher unemployment rates compared to the Flemish municipalities even just a few kilometers away.

Figure 2 uncovers the salient spatial patterns of commuting flows in Belgium, aggregating flows at the district level ${ }^{2}$. Only inter-district flows containing more than 3000 workers are shown and larger commuting flows are represented by thicker lines. Also here, the role of the central Capital Region of Brussels as the nation's most important employment center becomes clear from the web of commuting lines surrounding it. The northern city of Antwerp and the western city of Ghent play an important role for the northern region of Flanders. In the southern region of Wallonia, most commuting takes place between and around the cities of the industrial axis Mons-Charleroi-Liège. Notably, there is not one district-level commuting flow running between the northern region of Flanders and the southern region of Wallonia that contains more than 3000 workers. If one considers municipalities at a distance between 10 and $30 \mathrm{~km}$, there are 7.5 times less commuters between a pair of municipalities separated by the Flemish-Walloon regional border, as compared to similar pairs of municipalities within both regions. These findings are striking since there are no legal or administrative barriers to labor mobility across regions whatsoever.

The gravity model developed in this paper provides a framework to analyze the determinants

\footnotetext{
${ }^{2} \mathrm{~A}$ district or 'arrondissement' is the second smallest level of administrative regions in Belgium of which there are 43 in total.
} 


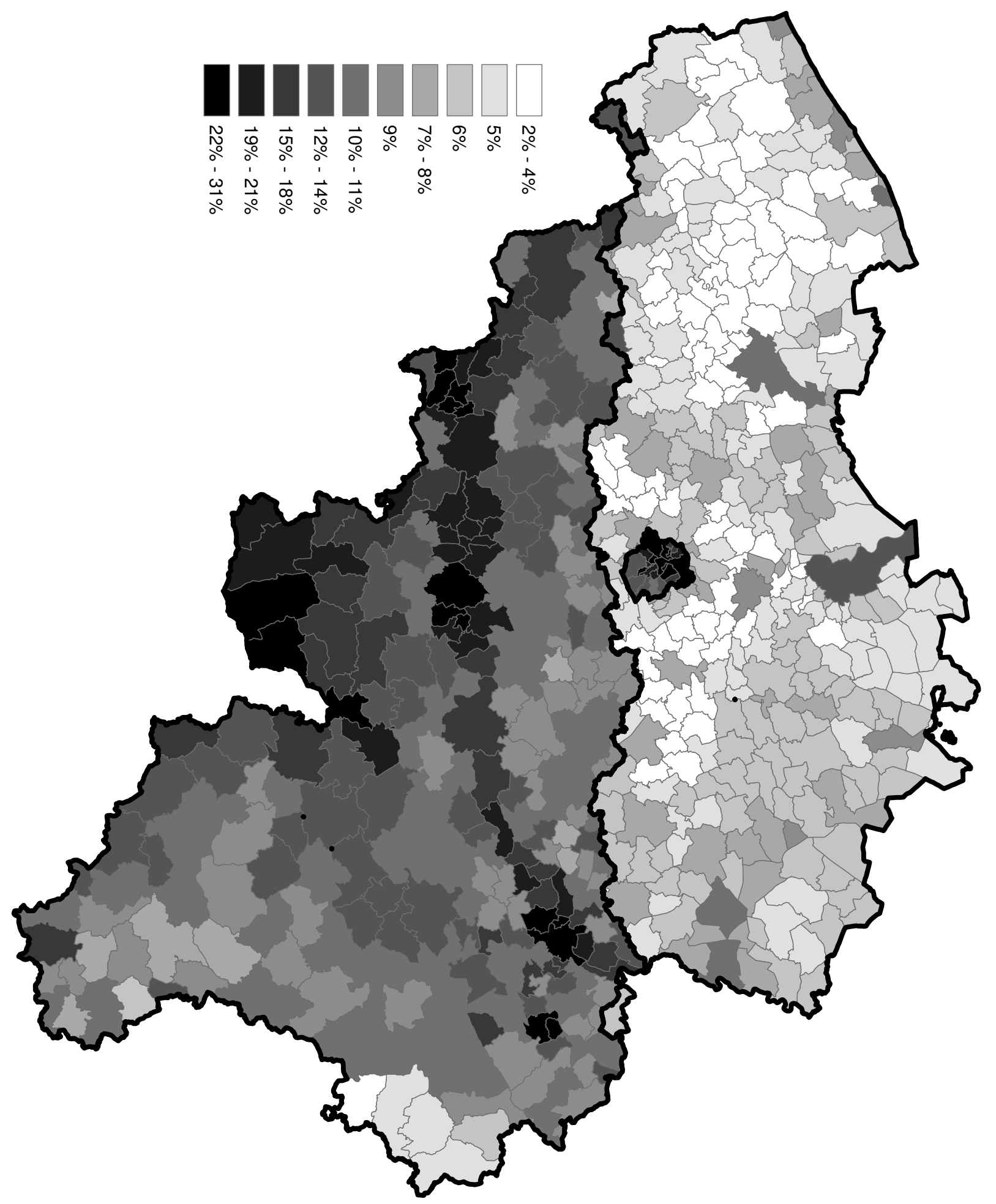

Figure 1: Unemployment rates for Belgian municipalities in 2008. Source: Steunpunt WSE 


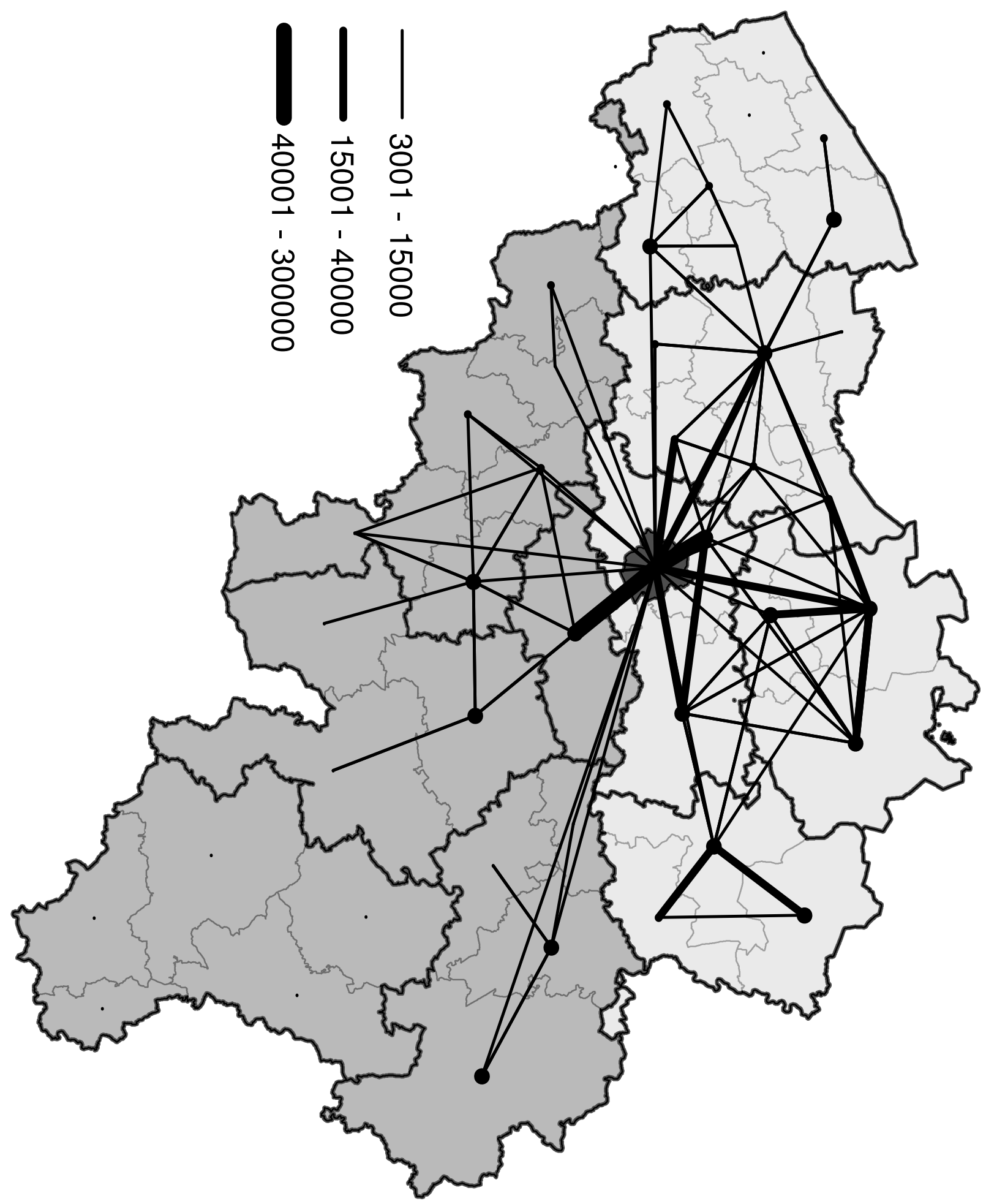

Figure 2: The main commuting flows in Belgium 
of the spatial structure of commuter flows that is illustrated in Figure 2. After controlling for factors such as the geographic distribution of workers and jobs, and the travel time by public transport and by car, it is found that regional borders remain a significant hurdle to commuting. Given the large disparities in local labor market performance, this suggests that a lot can be gained from policies which aim to reduce the deterrent effects of regional borders on commuting. The remainder of this paper is structured as follows: section 2 develops a micro-founded gravity equation and discusses our estimation strategy. Section 4 introduces the data and discusses the estimation results. Section 5 concludes.

\section{A micro-founded gravity equation for commuting}

Our empirical work employs a gravity equation, the origin of which can be traced back to Newton's law of universal gravitation. Newton modeled the force of gravity between two objects as a function of four variables: the distance between them, their masses and a constant term which he labeled the gravitational constant. The model outlined in this section will lead to a labor market analogue of Newton's law of gravity, modeling the size of a commuter flow between two localities. The model builds on Anderson and Van Wincoop (2003), who derive a gravity equation for international trade flows.

The labor supply of a locality is assumed to be fixed and workers are residentially immobile. Commuting is the only form of labor mobility available to workers. For the sake of simplicity, assume that each locality hosts a single firm. The firm operating in locality $d$ produces output $Y_{d}$ using a CES technology with differentiated labor as the sole input. Labor is differentiated across localities and $C_{o d}$ is the amount of labor from locality o used by the firm in locality $d$ :

$$
Y_{d}=\left(\sum_{o=1}^{R}\left(A_{o} C_{o d}\right)^{\frac{\sigma-1}{\sigma}}\right)^{\frac{\sigma}{\sigma-1}}
$$

where $A_{o}$ is a labor augmenting productivity term, reflecting differences in the productivity of the local workforce. The parameter $\sigma>1$ is the elasticity of substitution between workers from different localities. A firm from locality $d$ which minimizes costs conditional on some exogenous output level has the following demand for locality o's labor:

$$
w_{o d} C_{o d}=\left(\frac{w_{o d}}{A_{o} \Omega_{d}}\right)^{1-\sigma} \sum_{o=1}^{R} w_{o d} C_{o d}
$$


where $w_{o d}$ is the wage earned by workers commuting from $o$ to $d$, and

$$
\Omega_{d}=\left(\sum_{o=1}^{R}\left(\frac{w_{o d}}{A_{o}}\right)^{1-\sigma}\right)^{\left(\frac{1}{1-\sigma}\right)}
$$

is the wage index faced by firms in $d$. We will write $B_{d} \equiv \sum_{o=1}^{R} w_{o d} C_{o d}$ for firm d's total wage bill.

Commuting is costly, and hence a spatial equilibrium where all workers are indifferent to their location of work requires the firm in $d$ to pay a higher wage $w_{o d}$ to commuting workers from $o$, compared to the wage $w_{o}$ these workers would earn locally. We assume that commuting costs are a fixed proportion of wages, and write $\tau_{o d}-1>0$ for the commuting cost between $o$ and $d$ as a fraction of $w_{o}$. A spatial equilibrium then requires $w_{o d}=w_{o} \tau_{o d}$. Note that $\tau_{o d}$ can be interpreted as an implicit wasteful ad-valorem tax on commuting.

Next, write $E_{o}$ for the total earnings of all workers living in locality $o$

$$
E_{o} \equiv \sum_{d=1}^{R} w_{o d} C_{o d}
$$

Substituting equation (1) into (3) and using $w_{o d}=w_{o} \tau_{o d}$ allows to write local wages $w_{o}$ as:

$$
\left(\frac{w_{o}}{A_{o}}\right)^{1-\sigma}=\frac{E_{o}}{\sum_{d=1}^{R}\left(\frac{\tau_{o d}}{\Omega_{d}}\right)^{(1-\sigma)} B_{d}} .
$$

This in turn can be substituted into equation (1) to get:

$$
w_{o d} C_{o d}=\frac{E_{o}}{\sum_{d=1}^{R}\left(\frac{\tau_{o d}}{\Omega_{d}}\right)^{(1-\sigma)} B_{d}}\left(\frac{\tau_{o d}}{\Omega_{d}}\right)^{1-\sigma} B_{d},
$$

Next, define $Y^{T}$ as the total wage bill paid (and earned) in the economy, and define $b_{d}=B_{d} / Y^{T}$ and $e_{o}=E_{o} / Y^{T}$, which are the shares of $d$ 's wagebill and o's earnings, respectively, such that equation (5) becomes:

$$
w_{o d} C_{o d}=\frac{E_{o} B_{d}}{Y^{T}}\left(\frac{\tau_{o d}}{\Pi_{o} \Omega_{d}}\right)^{1-\sigma},
$$

with

$$
\Pi_{o}=\left(\sum_{d=1}^{R}\left(\frac{\tau_{o d}}{\Omega_{d}}\right)^{(1-\sigma)} b_{d}\right)^{\frac{1}{1-\sigma}} .
$$


After substituting the expression for $\left(A_{o} / w_{o}\right)^{(1-\sigma)}$ from equation (4) into equation (2), $\Omega_{d}$ can be written as:

$$
\Omega_{d}=\left(\sum_{o=1}^{R}\left(\frac{\tau_{o d}}{\Pi_{o}}\right)^{(1-\sigma)} e_{o}\right)^{\frac{1}{1-\sigma}}
$$

Equations (6) to (8) are the labor market equivalents of the AvW gravity model for trade flows. To express commuter flows in quantities, rather than monetary flows as customary in the international trade literature, we rewrite equation (6) in terms of number of workers, by using the fact that $w_{o d} C_{o d}=w_{o} \tau_{o d}$ and therefore $E_{o}=\sum_{d=1}^{R} w_{o d} C_{o d}=w_{o} \sum_{d=1}^{R} \tau_{o d} C_{o d}$ :

$$
C_{o d}=\frac{\bar{E}_{o} B_{d}}{Y^{T}} \tau_{o d}^{-\sigma}\left(\frac{1}{\Pi_{o} \Omega_{d}}\right)^{1-\sigma}
$$

where $\bar{E}_{o}=\sum_{d=1}^{R} \tau_{o d} C_{o d}$ is the new adjusted mass variable for the locality of origin.

Equation (9) is our final gravity equation. Together with equations (7) and (8), it represents a system of equations describing commuting flows which has been derived from a spatial labor market model. The origin mass variable equals the sum of all bilateral commuter flows originating from that locality, weighing each flow by its bilateral commuting costs. The mass variable of the locality of destination is simply its firm's total wage bill. These mass variables differ from the mass proxies commonly used in the existing literature on commuting. For example, Mathä and Wintr (2007), McArthur, Kleppe, Thorsen, and Ubøe (2011) and Melo, Graham, and Noland (2011), among others, proxy the mass variables by local population in the locality of origin and number of jobs in the locality of destination, respectively, whereas other authors (Guest and Cluett (1976), Flowerdew and Aitkin (1982)) simply control for the localities' total population.

In line with $\mathrm{AvW}$, the gravity equation contains an origin-specific term, $\Pi_{o}$, and a destination specific term, $\Omega_{d}$, which depend on all bilateral trade costs in the economy and on the distribution of economic activity around the origin and destination locality. These terms are similar to the factors which Anderson and Van Wincoop (2003) label 'multilateral resistance terms' in the context of international trade. We refer to them as 'MR-terms' hereafter. As emphasized by Anderson and Van Wincoop (2003), ignoring the MR-terms leads to biased parameter estimates.

Another possible determinant of the size of commuter flows are differences in the local skill level. To the extend that these differences are reflected in different average local productivities of workers $A_{o}$, however, such differences will be reflected in the average local wage levels $w_{o}$. Hence, the gravity equation allows for such differences in productivity between localities. 


\section{Estimation Strategy}

\subsection{MR terms and Commuting Costs}

Equations (7) and (8) only implicitly define $\Pi_{o}$ and $\Omega_{d}$. In order to obtain approximate but explicit solutions for $\Pi_{o}$ and $\Omega_{d}$, we follow Baier and Bergstrand (2009) and apply a first-order log-linear Taylor-series expansion to equations (7) and (8):

$$
\begin{aligned}
& \ln \Pi_{o}=-\sum_{d}^{R} b_{d} \ln \Omega_{d}+\sum_{d}^{R} b_{d} \ln \tau_{o d} \\
& \ln \Omega_{d}=-\sum_{o}^{R} e_{o} \ln \Pi_{o}+\sum_{o}^{R} e_{o} \ln \tau_{o d}
\end{aligned}
$$

Normalizing $\Omega_{d=1}=1$, this linear system of equations can be solved explicitly for $\ln \Pi_{o}$ and $\ln \Omega_{d}$ :

$$
\begin{array}{ll}
\ln \Pi_{o}=\sum_{d}^{R} b_{d} \ln \tau_{o d}+\sum_{k}^{R} e_{k} \ln \tau_{k 1}-\sum_{k}^{R} \sum_{m}^{R} e_{k} b_{m} \tau_{k m} & o=2, \ldots, R \\
\ln \Omega_{d}=\sum_{o}^{R} e_{o} \ln \tau_{o d}-\sum_{k}^{R} e_{k} \ln \tau_{k 1} & d=2, \ldots, R
\end{array}
$$

The second term of equations (10) and (11) stems from the fact that $\Omega_{d=1}$ was normalized to one, and the third term of equation (10) scales $\Pi_{o}$ to account for the normalization on $\Omega_{d}$.

\subsection{Count model and latent back-fitting}

Using equations (10) and (11), a log-linearized version of the gravity equation (9) could be estimated by OLS. But as argued by Silva and Tenreyro (2006) this approach is problematic for two reasons: first, Jensen's inequality implies that, in the presence of heteroskedasticity, log-linear transformations will cause the error term to become correlated with the covariates. ${ }^{3}$ Second, by log-transforming equation (9), all observations with a commuter flow equal to zero drop out of the analysis. This is the case for about 65 percent of all observations in our sample. This type of censoring leads to sample selection bias. To overcome both problems, we treat commuter flows as count data. Count models explicitly allow for zero as a possible (and likely) outcome and do not suffer from bias in the presence of heteroskedasticity. We use a

\footnotetext{
${ }^{3}$ Silva and Tenreyro (2006) note that that the expected value of the logarithm of a random variable depends on its variance. So, in the presence of heteroskedasticity, where the variance of the error term depends on the covariates, the expected value of the logarithm of that error term depends on the regressors, hence violating the consistency condition of OLS, leading to biased estimation.
} 
negative binomial model which allows the variation of the count variable to exceed its mean (overdispersion). ${ }^{4}$

Assume that commuting costs are a log-linear function of geographical distance (dist $\left.t_{o d}\right)$ and a dummy capturing the effect of regional borders $\left(B_{o d}\right)$, such that

$$
\tau_{o d}=\operatorname{dist}_{o d}^{\alpha_{1}} e^{\alpha_{2} B_{o d}} \quad \text { or } \quad \ln \tau_{o d}=\alpha_{1} \ln \text { dist }_{o d}+\alpha_{2} B_{o d}
$$

For within-locality commuting, the 'internal distance' dist ${ }_{i i}$ is assumed to be directly proportional to the square root of the area of each municipality, and calculated according to the formula dist $_{i i}=(2 / 3) \sqrt{\text { area }_{i} / \pi}$, as in Head and Mayer (2000).

Using the approximations of $\Pi_{o}$ and $\Omega_{d}$ given by equations (10) and (11), the stochastic negative binominal model for the gravity equation (9) is given by:

$$
\begin{aligned}
C_{o d} & \sim \operatorname{Poisson}\left(\exp \left(\eta_{o d}+v_{o d}\right)\right) \\
e^{v_{o d}} & \sim \operatorname{Gamma}(1 / \gamma, \gamma) \\
\eta_{o d} & =-\ln Y^{T}+\ln \bar{E}_{o}+\ln B_{d}-\sigma \alpha_{1} \ln \operatorname{dist}_{o d}-\sigma \alpha_{2} B_{o d} \\
& +(\sigma-1)\left(\sum_{m}^{R} b_{m}\left(\alpha_{1} \ln \text { dist }_{o m}+\alpha_{2} B_{o m}\right)-\sum_{k}^{R} \sum_{m}^{R} e_{k} b_{m}\left(\alpha_{1} \ln \operatorname{dist}_{k m}+\alpha_{2} B_{k m}\right)\right) \\
& +(\sigma-1)\left(\sum_{k}^{R} e_{k}\left(\alpha_{1} \ln \operatorname{dist}_{k d}+\alpha_{2} B_{k d}\right)\right),
\end{aligned}
$$

where $\gamma$ is the overdispersion parameter, $\bar{E}_{o}=\sum_{d=1}^{R} \tau_{o d} C_{o d}$ and $B_{d}=\sum_{o=1}^{R} w_{o d} C_{o d}$.

Model (13) can not be straightforwardly estimated as it contains 3 latent variables, $\bar{E}_{o}$ and the two MR-terms $\Pi_{o}$ and $\Omega_{d}$, which depend on the unknown parameters governing the transport costs, $\alpha_{1}$ and $\alpha_{2}$. However, the relationship between the $\alpha$ 's and $\sigma$ imposed by the model offers a way around this, in combination with a latent backfitting procedure (see Pastorello, Patilea, and Renault, 2003). Initially, assume $\alpha_{1}=\alpha_{2}=1$ to calculate first-round estimates of the origin's mass variable and MR terms. Estimating model (13) then provides first-round estimates of $\sigma \alpha_{1}, \sigma \alpha_{2}$ and $\sigma-1$, from which first-round approximations of the parameters $\alpha_{1}, \alpha_{2}$ and $\sigma$ can be calculated. These parameters are used to construct secondround estimates of the mass variables and MR-terms. Re-estimating the model then provides second-round estimates of $\alpha_{1}, \alpha_{2}$ and $\sigma$. This process is repeated until convergence is achieved.

\footnotetext{
${ }^{4}$ The critique of Bosquet and Boulhol (2010) on the use of the negative binomial model does not apply in this context as our dependent variable, the number of commuters, is scale independent.
} 
This estimation technique allows us to identify all the model's parameters, such as the contribution of each element of $\tau_{o d}$ (the $\alpha$ 's), but also $\sigma$, the elasticity of substitution between workers from different localities. To our knowledge, we are the first to identify such an elasticity.

\subsection{Comparative Statics}

Estimation of model (13) provides consistent estimates of the model parameters. However, the coefficient on the border dummy $-\sigma \alpha_{2}$ does not correspond to the percentage change in commuting due to the presence of the border as in a standard regression. The ceteris-paribus condition is violated because other variables in the model change depending on the absence or presence of a border (see AvW and Feenstra, 2004). As in AvW we consider only the direct changes in the MR terms $\Pi_{o}$ and $\Omega_{d}$ due to the borders when calculating comparative statics, and ignore changes in the shares $e_{o}$ and $b_{d}$ and the mass variables.

Define the 'border effect', $X_{o d}$, as the percentage difference between a commuter flow $C_{o d}$ between two localities $o$ and $d$ which are separated by a border $\left(B_{o d}=1\right)$, and the commuter flow $C_{o d}^{*}$ in the hypothetical case in which the effect of a set of borders $B_{i j}$, including $B_{o d}$, is removed. From equation (9) and (12) it follows that

$$
X_{o d}=\frac{C_{o d}-C_{o d}^{*}}{C_{o d}^{*}}=\frac{\left(\Pi_{o} \Omega_{d}\right)^{\sigma-1}}{\left(\Pi_{o}^{*} \Omega_{d}^{*}\right)^{\sigma-1}} e^{-\sigma \alpha_{2}}-1,
$$

where $\Pi_{o}^{*}$ and $\Omega_{d}^{*}$ are the recalculated multilateral resistance terms, setting some $B_{i j}=0$. Obviously, the border effect $X_{o d}$ is only defined for localities that are seperated by a border $\left(B_{o d}=1\right)$.

\section{The effect of regional borders on commuting}

\subsection{Data description}

Highly disaggregated data on the number of daily commuters between 580 Belgian municipalities ${ }^{5}$ was obtained from the Belgian National Social Security Office (NSSO) for the year 2008. This administrative source covers the total Belgian population of payroll employment, but excludes the self-employed. 76 percent of the Belgian payroll workers work in a different municipality than the one they live in. 16 percent of them work in a different NUTS1 region.

\footnotetext{
${ }^{5}$ Nine municipalities belonging to the small German speaking community of Belgium were excluded from the analysis, to avoid complicating the empirical application. This leaves 580 out of a total of 589 Belgian municipalities in the sample.
} 
Our unit of analysis is the number of commuters between pairs of municipalities. Including within-municipality commuting flows, our dataset consists of 336400 datapoints. Of these pairs 217721 or about 65 percent do not have any commuting between them.

The data also contains the average wage paid by the firms in a municipality. This allows to calculate the total wage bill in each municipality, which serves as the mass variable of destination. The origin mass variable, in contrast, has to be calculated iteratively in the estimation procedure as described in section 3.2.

The analysis includes three different measures of intermunicipality distance. A first proxy is the geographical distance ( dist $_{\text {od }}$ ) between the town halls of both municipalities. Additionally, we consider travel time by car $\left(c a r_{o d}\right)$, obtained through the Google Maps API, and travel time by public transport ( pubtrans $_{o d}$ ), obtained from the website of the main Belgian train operator, NMBS. ${ }^{6}$ Travel time is more relevant to commuters than the geographic distance, and controls for factors such as the quality of transport infrastructure.

\subsection{Estimation results, base specification}

Table 1 presents the results of estimating different versions of the model (equation (13)). The dummy variable otherreg $_{\text {od }}$ indicates whether the commuter flow crosses one of the regional borders between Brussels, Flanders and Wallonia. Which border is crossed, or the direction wherein, is not taken into account. As such, commuting costs are assumed to be symmetric, an assumption that will be relaxed later on. Column (I) of Table 1 shows the specification of a basic gravity equation where the size of an intermunicipality commuting flow is simply a function of the two mass variables derived from the model, geographic distance between the town halls of both municipalities and a dummy, otherreg ${ }_{\text {od }}$, which indicates whether the two municipalities are separated by a regional border. The coefficients on the mass variables are estimated close to unity, as predicted by theory. The effect of distance is clearly negative, as expected. The large and negative coefficient on otherreg $_{\text {od }}$ shows that, after controlling for distance and the mass of the origin and destination, on average the regional borders act as an additional barrier to commuters. Using expression (14), while ignoring the MR-terms, the estimated effect of the

\footnotetext{
${ }^{6}$ Public transport times refers to the shortest travel time to get to the destination at 8.30am on a Tuesday morning, combining all forms of public transport such as train, bus and underground. The data on travel times reflect the situation in June 2011. For intra-municipality travel times, a regression was first performed of travel time on a fifth order polynomial of distance, using data on short-distance intermunicipality commuting, to uncover the relationship between travel time and distance. Using this relationship, the within-municipality travel times were then estimated, starting from the internal distance measure dist $_{i i}=(2 / 3) \sqrt{\text { area }_{i} / \pi}$. Our results do not change much when using other proxies for internal distance and travel time, or simply excluding within-municipality commuting from the analysis altogether.
} 


\begin{tabular}{lccc}
\hline \hline & (I) & (II) & (III) \\
\hline otherreg & -0.946 & -0.787 & -0.494 \\
& $(0.00670)$ & $(0.00636)$ & $(0.00610)$ \\
logmassA & 0.909 & 0.897 & 0.968 \\
& $(0.00455)$ & $(0.00430)$ & $(0.00412)$ \\
logwagebillB & 1.031 & 0.948 & 1.007 \\
& $(0.00258)$ & $(0.00237)$ & $(0.00221)$ \\
logdist & -1.887 & & \\
& $(0.00425)$ & & \\
logpubtrans & & -0.499 & -0.539 \\
& & $(0.0125)$ & $(0.0129)$ \\
logcar & & -2.469 & -2.689 \\
& & $(0.0120)$ & $(0.0122)$ \\
MRa & & & 0.359 \\
& & & $(0.00332)$ \\
MRb & & & 0.359 \\
& & & $(0.00332)$ \\
constant & & & -19.76 \\
& $(0.0765)$ & $(0.0556)$ & $(0.0508)$ \\
\hline \hline Robust standard errors in parentheses & &
\end{tabular}

Table 1: Estimating the gravity equation for commuting, with a single border-crossing dummy otherreg indicating any inter-regional border crossing.

borders on commuting from specification (I) is $X_{o d}=\exp (-0.946)-1=-0.61$, or about -61 percent.

Column (II) replaces the simple distance measure by two distance variables more relevant to commuters, travel time by car $\left(\mathrm{car}_{o d}\right)$ and public transport (pubtrans $s_{\text {od }}$ ). Both variables are included in logs. The time it takes to commute between two municipalities by car is clearly the most important determinant of the two. A 10 percent increase in travel time by car, reduces the commuter flow by 25 percent, whereas for travel time by public transport, this is only 5 percent. This finding is not surprising since driving by car is by far the most popular transport mode for the Belgian commuters. ${ }^{7}$ Note that after controlling for the two alternative distance measures, the absolute value of the coefficient on the border dummy decreases, implying that part of the regional border effect captured in column (I) is due to poor interregional transport infrastructure connecting municipalities across regional borders. The results in column (II) show an estimated border effect of -54 percent $(\exp (-0.787)-1)$.

Column (III) adds the MR-terms and is the first specification to fully correspond to model

${ }^{7}$ A 2008 survey conducted by the Federal Administration of mobility revealed that 68 percent of Belgian employees commute by car, whereas only 16.6 percent use public transportation. 


\begin{tabular}{ll}
\hline \hline $\mathrm{BR} \Rightarrow \mathrm{VL}$ & -0.34 \\
$\mathrm{BR} \Rightarrow \mathrm{WL}$ & -0.31 \\
$\mathrm{VL} \Rightarrow \mathrm{BR}$ & -0.32 \\
$\mathrm{VL} \Rightarrow \mathrm{WL}$ & -0.34 \\
$\mathrm{WL} \Rightarrow \mathrm{BR}$ & -0.29 \\
$\mathrm{WL} \Rightarrow \mathrm{VL}$ & -0.34 \\
\hline Mean & -0.32 \\
\hline \hline
\end{tabular}

Table 2: The effect of regional borders on commuting, calculated using equation (14) with the results from specification (III) in Table 1 . The effects differ between regions only because of changes in the MR-terms.

(13). The coefficients on $\ln \Pi_{o}$ and $\ln \Omega_{o}$ are constrained to be equal, as implied by the model. Due to the role of the MR-terms, the border effects in equation (14) now differ per region of origin and destination. Table 2 shows the estimated external border effect per origin-destination region pair, using equation (14) while setting all borders $B_{i j}=0$ when calculating $\Pi_{o}^{*}$ and $\Omega_{d}^{*}$. Taking the weighted average (with the weights being the number of municipalities within each region) of the six border effects shows that the border effect now reduces to about -32 percent. Failing to control for the MR terms leads to a substantial overestimation of the border effect, which is consistent with the findings of Anderson and Van Wincoop (2003) and subsequent contributions to this literature.

\subsection{Estimation results, relaxing assumptions on commuting costs}

Specifications (I), (II) and (III) in Table 1 are rather similar to the gravity equations which are commonly used the context of international trade. We will now alter these specifications to better match the specific needs of a labor market model.

First, we want to relax the assumption that the effects of borders are identical, irrespective of which border is crossed, and the direction in which it is crossed. This assumption is clearly untenable in the context interregional commuting. As an example, the fact that knowledge of French as a second language is more common in the Flanders than the knowledge of Dutch in Wallonia could cause the Flemish-Walloon regional border to exert a larger deterrent effect on commuting from Wallonia to Flanders, compared to commuting flows in the opposite direction. We therefore replace the otherreg border dummy in the regression with 6 border dummies, one for each of the possible border crossings between the three NUTS-1 level regions in Belgium.

Second, there might be many omitted region-specific factors which affect commuting behavior, such as regional culture, policy, or differential preferences of commuters regarding 
modes of transportation. Failing to control for such factors will lead the coefficients on the directional border crossing dummies to be biased as they will pick up this region specific distance decay heterogeneity (see also Melo, Graham, and Noland, 2011). We therefore allow the effect of travel time by car and train to differ between regions. Additionally, we control for differences in the average size of outgoing commuting flows between the three NUTS1 regions, by adding a separate constant term for each region of origin. Table 3 presents the estimation results. Table 4 translates the estimates from Table 3 into comparative statics, by applying equation (14). Before, we compared the situation where all border effects were in place to the situation where all border effects were set to zero. Now, we remove the borders one-byone and report the results separately. The result reported for the $\mathrm{BR} \Rightarrow \mathrm{VL}$ border crossing therefore correspond to the percentage change in commuting across the $\mathrm{BR} \Rightarrow \mathrm{VL}$ border in the hypothetical case where only this specific border would no longer have an effect on commuting. The results in table 4 show that the border effect varies widely between regions and depending on the direction in which borders are crossed.

The commuting flows towards the Brussels region ( $\mathrm{WL} \Rightarrow \mathrm{BR}$ ) and $(\mathrm{FL} \Rightarrow \mathrm{BR})$ are not much affected by the regional borders. This is not very surprising. Brussels, being the capital region, serves as the central economic hub of Belgium and hosts an important share of Belgium's economic activity. Linguistic differences are not as much of a concern for this border crossing as for the others, since many jobs in Brussels require the knowledge of French or Dutch, or both. Also, arguably, the cultural divide between Brussels and the other two regions is less likely to be an obstacle for incoming commuter flows, as its capital status and history causes the inhabitants of both regions to feel connected to Brussels. This special role for Brussels in the Belgian interregional commuting flows was already visible in Figure 2.

The $\mathrm{WL} \Rightarrow \mathrm{FL}$ border effect reduces commuter flows by 58 percent. For the $\mathrm{FL} \Rightarrow \mathrm{WL}$ border crossing, this effect is only 32 percent. Apparently, the implied commuting costs of the $\mathrm{WL} \Rightarrow \mathrm{FL}$ border crossing exceed those of the $\mathrm{FL} \Rightarrow \mathrm{WL}$ border. This differential effect can be simply due to regional differences in the knowledge of Dutch and French respectively. Alternatively, it might be due to different attitudes of workers with regard to commuting to the other region.

Turning to the border crossings by commuters originating from Brussels, first notice that the $\mathrm{BR} \Rightarrow \mathrm{FL}$ effect is negative: intermunicipality commuter flows crossing this border are on average 39 percent smaller due to the border effect. As mentioned before, the majority of the Brussels' population is French speaking, so also in this case, deficiencies in the knowledge of Dutch probably are important. The $\mathrm{BR} \Rightarrow \mathrm{WL}$ border effect, perhaps surprisingly, is positive and large, implying that, even after controlling for economic conditions in the origin and 


\begin{tabular}{|c|c|}
\hline $\operatorname{logmass} A$ & $\begin{array}{c}0.967^{* * *} \\
(0.00403)\end{array}$ \\
\hline logwagebillB & $\begin{array}{c}0.984^{* * *} \\
(0.00219)\end{array}$ \\
\hline MRa & $\begin{array}{c}0.346^{* * *} \\
(0.00406)\end{array}$ \\
\hline $\mathrm{MRb}$ & $\begin{array}{c}0.346^{* * * *} \\
(0.00406)\end{array}$ \\
\hline logtrainBR & $\begin{array}{c}-0.207^{* * * *} \\
(0.0592)\end{array}$ \\
\hline logtrainFL & $\begin{array}{c}-0.362^{* * *} \\
(0.0155)\end{array}$ \\
\hline logtrainWL & $\begin{array}{c}-0.565^{* * *} \\
(0.0173)\end{array}$ \\
\hline logcarBR & $\begin{array}{c}-2.358^{* * *} \\
(0.0439)\end{array}$ \\
\hline logcarFL & $\begin{array}{c}-2.828^{* * *} \\
(0.0150)\end{array}$ \\
\hline logcarWL & $\begin{array}{r}-2.538^{* * *} \\
(0.0167)\end{array}$ \\
\hline $\mathrm{VL} \Rightarrow \mathrm{WL}$ & $\begin{array}{c}-0.474^{* * *} \\
(0.0115)\end{array}$ \\
\hline $\mathrm{VL} \Rightarrow \mathrm{BR}$ & $\begin{array}{l}0.0517^{* * *} \\
(0.0101)\end{array}$ \\
\hline $\mathrm{WL} \Rightarrow \mathrm{VL}$ & $\begin{array}{c}-1.072^{* * *} \\
(0.0109)\end{array}$ \\
\hline $\mathrm{WL} \Rightarrow \mathrm{BR}$ & $\begin{array}{l}0.0562^{* * * *} \\
(0.0122)\end{array}$ \\
\hline $\mathrm{BR} \Rightarrow \mathrm{VL}$ & $\begin{array}{c}-0.580^{* * *} \\
(0.0457)\end{array}$ \\
\hline $\mathrm{BR} \Rightarrow \mathrm{WL}$ & $\begin{array}{c}0.304^{* * *} \\
(0.0500)\end{array}$ \\
\hline
\end{tabular}

Table 3: Estimating the gravity equation for commuting, with a separate border-crossing dummy for each regional-border crossing.

destination municipalities and their surroundings, as well as transport infrastructure, the results indicate excess interregional commuting. The special geographical situation of the Brussels region provides a straightforward explanation: it is an enclave with a dominantly French-speaking population within the unilingual Dutch-speaking region of Flanders. It is not very surprising that its residents are 'unexplainably' tending to commute to the more remote but monolingual French speaking region of Wallonia, even after controlling for economic factors 


\begin{tabular}{lr}
\hline \hline $\mathrm{BR} \Rightarrow \mathrm{VL}$ & -0.39 \\
$\mathrm{BR} \Rightarrow \mathrm{WL}$ & 0.33 \\
$\mathrm{VL} \Rightarrow \mathrm{BR}$ & 0.04 \\
$\mathrm{VL} \Rightarrow \mathrm{WL}$ & -0.32 \\
$\mathrm{WL} \Rightarrow \mathrm{BR}$ & 0.05 \\
$\mathrm{WL} \Rightarrow \mathrm{VL}$ & -0.58 \\
Mean & -0.40 \\
\hline \hline
\end{tabular}

Table 4: The effect of regional borders on commuting, calculated using equation (14) with the results from Table 3. The effects differ per region because of changes in the MR-terms as before, but now mainly because of the separate border-dummies per border crossing in the gravity equation.

such as travel time and economic mass. Another possible cause of the positive border effect could be differences in the skill structure of both regions, and a lack of demand of a specific type of workers in the municipalities located in the Brussels region induces workers to cross the border and find a job in Walloon municipalities. However, to the extend that these differences in the skill structure is reflected in different average productivity levels in the municipalities, and hence, different average municipality wage levels, section 2 shows that these effects would be picked up by the mass variables derived from the structural labor market model.

Finally, the estimation method allows us, for the first time, to retrieve parameter estimates of the elasticity of substitution between workers from different municipalities, the value of which is 1.346 in our final estimation. Because there are no comparable estimates from previous studies, it is difficult to gauge the plausibility of this parameter value. Goos, Manning, and Salomons (2010), confronted with the same problem, list a number of studies that report comparable estimates of EoS between different types of workers. The authors themselves find an EoS between 1.2 and 9.09 for substitution between groups of workers with a different educational attainment. Katz and Murphy (1992) find an EoS between two educational groups of 1.4. Similarly, David and Lemieux (2001) find values ranging from 1.1 to 2.5. Our estimated value of about 1.3 is rather at the lower side of the range. The relatively low value of the EoS suggest that workers from different municipalities are far from perfect substitutes. This finding can reflect differences in the skills of workers from different municipalities, for example.

\subsection{The effect of borders on wages}

Given the spatial structure of our model, the labor market equilibrium in every locality depends directly on the local labor demand and supply, on the demand and supply in the surroundings and on the spatial pattern of commuting costs. Equation (4) is an explicit 
expression for the equilibrium wage in a locality. It shows that local wages $w_{o}$ increase when the demand for labor in the local or nearby localities increases. A decrease in bilateral commuting costs between $o$ and other localities will increase $w_{o}$ and this effect is stronger if localities connected to $o$ have a high labor demand. In our model, wages act as a measure of the centrality and attractiveness of a location in the spatial labor market. The local wage summarizes in a single value the effect of regional borders and all other variables on the commuting flows to and from a municipality.

As border crossings represent a significant hurdle to commuting, removing borders changes the spatial pattern of commuting costs. This in turn will affect the 'centrality' and wage-levels of all locations. In this section we will quantify this wage effect of borders. As local wages are also affected by the productivity of the local labor force, which is unobservable, we do not consider the local level of wages, but focus solely on predicted changes in wages in response to changes in border effects. Accordingly, we illustrate how the attractiveness of locations would change. As before, we will only take into account direct changes in the transport costs, and their effect on the MR-terms $\left(\Omega_{d}\right.$ in expression (4)). Our analysis therefore is partial in nature.

The left panel of figure 3 shows the result of this exercise, plotting the ratio of wages calculated according to (4), relative to the case where all border effects are set to zero. Note that for commuting from and to Brussels, this exercise might not be very informative, as it is not clear which type of policy can or should aim to remove positive border effects. Nevertheless, it clearly emerges that the predicted effect of removing regional borders on wages is large and rather homogeneous within regions. The estimated increase in wages is between 5 and 10 for most municipalities in Flanders; between 10 and 20 percent for Brussels; and a very large estimated effect between 40 and 65 percent for Wallonia. To explain the intuition behind the pattern revealed by figure 3, consider the case of Flanders and Wallonia. From a demand perspective, the elimination of the $\mathrm{FL} \Rightarrow \mathrm{WL}$ and $\mathrm{WL} \Rightarrow \mathrm{FL}$ borders will increase wages in both regions, as demand for cross border workers rises. Since the $\mathrm{WL} \Rightarrow$ FL border effect was stronger than the $\mathrm{FL} \Rightarrow \mathrm{WL}$ border effect, this increase will be more pronounced in the Wallonian region. This differential effect is enhanced by the fact that employment opportunities are on average relatively abundant in the Flemish municipalities, as compared to those in Wallonia.

The estimated wage-effects shown in the left panel of Figure 3 are implausibly large, especially for municipalities located far from the border. These results are highly dependent on the value of the estimated elasticity of substitution in the model. Replacing the estimate $\hat{\sigma}=1.346$ with $\hat{\sigma}=2.3$ results in a markedly more localized wage-effect from removing the borders. The result of this alternative scenario is shown in the right panel of Figure 3. 

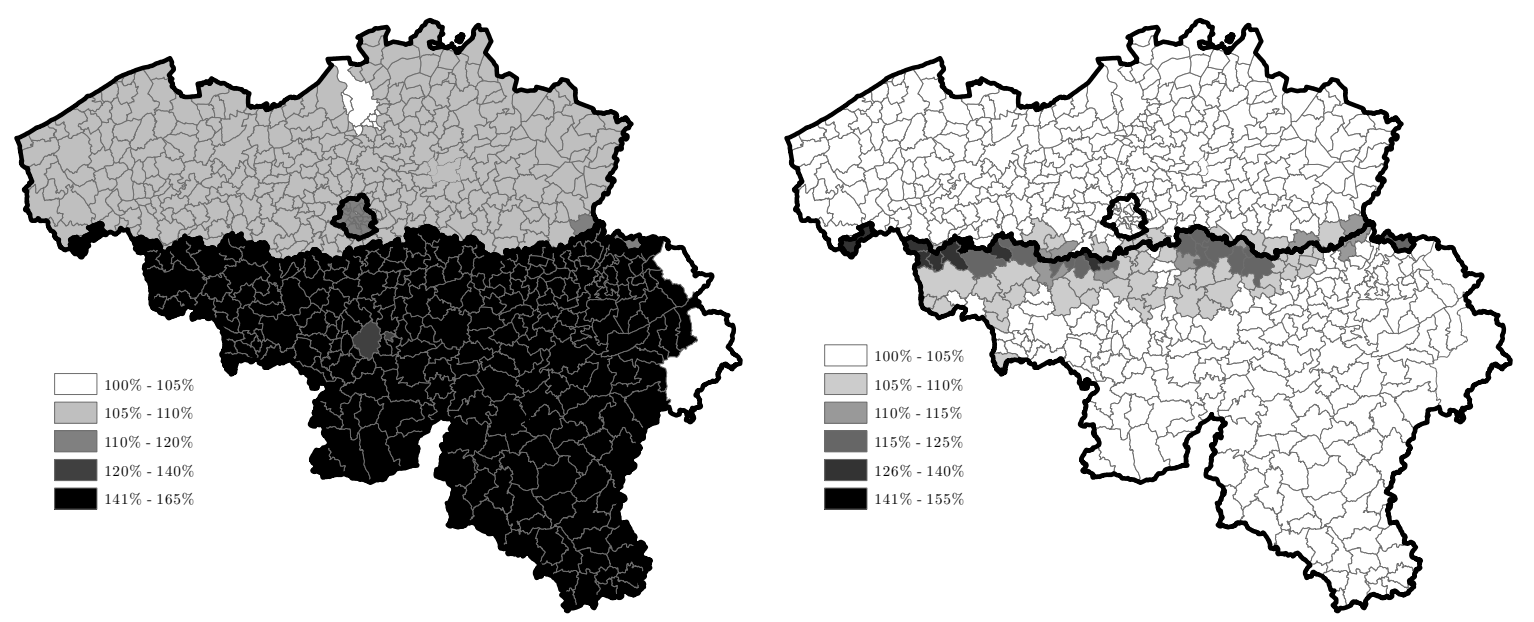

Figure 3: The predicted wage-effect of removing regional borders. The left panel uses the estimated value for $\sigma$ of 1.346. The right panel imposes an ad-hoc value of 2.3.

This figure reveals the geographic variation in the impact of removing the borders. There is a significant predicted effect on Flemish municipalities in the south of Limburg, which is the most eastern province of Flanders (especially in the Flemish 'exclave' municipality of Voeren, the most eastern Flemish municipality); and in some Flemish municipalities to the far south-west of Brussels. Employment opportunities in both these regions are relatively limited. In Wallonia, the estimated effect is more pronounced, and extends to several communities which do not directly border Flanders. The estimated effect is stronger in the region north-west of Wallonia (province of Hainaut), which is adjacent to the province of West-Flanders, a prosperous region characterized by a strong labor demand. The part of Wallonia south of Brussels is less affected by the removal of the border effects, as it has markedly better employment opportunities, both locally, and in nearby Brussels.

In conclusion, when using the estimated elasticity of substitution between labor from difference municipalities from the model, the predicted effect of removing the border on wages seems very high, and decays only slowly with distance to the border. This strong effect is interesting but simultaneously presents a puzzle. Imposing a higher elasticity of substitution results in a more spatially differentiated border effect, with effects on wages which are larger in more depressed regions with nearby employment opportunities across a regional border.

\section{Summary and Conclusion}

In this paper, we derived a gravity equation for commuting from a simple spatial labor market model. Many studies have estimated commuting gravity models before us, but to the 
best of our knowledge this study is the first to structurally derive a relationship explaining the size of commuter flows running between localities. This approach allows us to tackle several problems associated with more ad-hoc approaches to estimating gravity equations, which have been uncovered in the context of the estimation of gravity equations for international trade.

Our model is based on Anderson and Van Wincoop (2003), who derived a gravity equation for international trade flows. This model-based approach allows to derive the correct control variables and shows the importance of controlling for the economic surrounding of two regions. Neglecting these issues results in estimation bias. By using the linear approximation method developed by Baier and Bergstrand (2009), we obtained an estimable gravity equation.

Our final gravity equation explains commuting by the size of labor supply and demand in origin and destination, two 'multilateral resistance' terms expressing how both the origin and destination relate to their economic environment, and a vector of commuting cost variables. In our empirical application we took great care to construct good proxies for commuting costs, including commuting time by car and public transportation. The gravity equation is estimated by means of a negative binomial regression technique, using a latent back-fitting procedure to account for the presence of latent variables. This way all the model parameters can be estimated consistently, including the elasticity of substitution between workers from different regions.

The model was subsequently estimated using a Belgian dataset containing commuter flows between 580 Belgian municipalities. Belgium is an interesting country for the study of regional borders and their effect on commuting, as the country is multi-regional and multi-lingual, and even a casual look at the pattern of commuting flows reveals interesting regional patterns.

The model was first estimated assuming symmetric commuting costs. After controlling for differences in local economic conditions, as well as omitted multilateral resistance terms, there is still a significant and large deterrent effect of regional borders on the size of intermunicipality commuting flows. We show that failing to control for the economic surrounding of regions leads to an overestimation of the border effect. In a next step, we allow for asymmetric border effects by taking into account the direction in which a border is crossed. The analysis reveals the border effect is highly dependent on which border is crossed, and even in which direction.

Our results show that regional borders act as a strong barrier to commuters. These barriers function as an implicit and wasteful tax on cross-border commuting. Hence, reducing them would lead to significant welfare gains, especially in depressed localities close to employment opportunities in a neighboring region. Only a small fraction of these effects are explained by a lack of interregional transportation infrastructure. The fact that the effects of borders are 
asymmetric and depend on the direction in which a border is crossed strongly suggests that there is scope for policy to encourage interregional commuting and reap the benefits from more regional labor market integration.

\section{References}

Anderson, J., And E. Van Wincoop (2003): "Gravity with Gravitas: A Solution to the Border Puzzle," The American Economic Review, 93(1), 170-192.

BAier, S., AND J. Bergstrand (2009): "Bonus vetus OLS: A simple method for approximating international trade-cost effects using the gravity equation," Journal of International Economics, 77(1), 77-85.

Bosquet, C., AND H. Boulhol (2010): "Scale-dependence of the Negative Binomial Pseudo-Maximum Likelihood Estimator," GREQAM Document de Travail, 39.

David, C., AND T. Lemieux (2001): "Can Falling Supply Explain the Rising Return to College for Younger Men? A Cohort-Based Analysis," Quarterly Journal of Economics, 116(2), 705-746.

Feenstra, R. (2004): Advanced international trade: theory and evidence. Princeton University Press.

Flowerdew, R., AND M. Aitkin (1982): "A method of fitting the gravity model based on the Poisson distribution," Journal of Regional Science, 22(2), 191-202.

Fotheringham, A. (1981): "Spatial structure and distance-decay parameters," Annals of the Association of American Geographers, 71(3), 425-436.

Goos, M., A. Manning, And A. SALomons (2010): "Explaining job polarization in Europe: The roles of technology, globalization and institutions," CEP Discussion Papers.

Guest, A., AND C. Cluett (1976): "Workplace and residential location: A push-pull model," Journal of Regional Science, 16(3), 399-410.

HeAD, K., AND T. MAYer (2000): "Non-Europe: The magnitude and causes of market fragmentation in the EU," Review of World Economics, 136(2), 284-314.

JAnssens, R. (2008): "Taalgebruik in Brussel en de plaats van het Nederlands. Enkele recente bevindingen," Brussels Studies, 13, 15.

Katz, L., AND K. Murphy (1992): “Changes in relative wages, 1963-1987: supply and demand factors," The Quarterly Journal of Economics, 107(1), 35-78.

MAthä, T., AND L. WinTR (2007): “Commuting flows across bordering regions: a note," Applied Economics Letters, 16(7), 735-738.

McArthur, D., G. Kleppe, I. Thorsen, AND J. Ubøе (2011): “The impact of monetary costs on commuting flows," Papers in Regional Science.

Melo, P., D. Graham, AND R. Noland (2011): "The effect of labour market spatial structure on commuting in England and Wales," Journal of Economic Geography.

Pastorello, S., V. Patilea, And E. Renault (2003): "Iterative and recursive estimation in structural nonadaptive models," Journal of Business and Economic Statistics, 21(4), 449-509.

Silva, J., And S. Tenreyro (2006): “The log of gravity," The Review of Economics and Statistics, 88(4), 641-658.

Thorsen, I., AND J. Gitlesen (1998): "Empirical evaluation of alternative model specifications to predict commuting flows," Journal of Regional Science, 38(2), 273-292. 
ToRfS, W. (2008): “De Arbeidsmarkt(en) in België: Evolutie,Vergelijk en Stand van Zaken anno 2007," Vives Policy Paper. 